\title{
Gut
}

Leading article

\section{Gastro-oesophageal reflux and asthma; a common association, but of what clinical importance?}

The association between gastro-oesophageal reflux and respiratory disease has been appreciated since 1848 when Simpson described a patient who died of aspiration pneumonia after an anaesthetic. The concept of spillover of gastric contents into the lung in patients because of abnormal oesophageal function is well accepted, but the link between gastro-oesophageal reflux and asthma is less well understood. In 1935 Bray' suggested that gastric distension caused by dietary indiscretion could lead to reflex mediated bronchoconstriction in asthmatics. In the 1970s several reports suggested that in patients with gastro-oesophageal reflux and asthma, surgery to restore the competence of the lower oesophageal sphincter improved respiratory symptoms. These studies were poorly controlled and evaluation of respiratory function was poor but they stimulated a period of aggressive investigation and treatment of oesophageal dysfunction in asthmatics. As with many such fashions enthusiasm waned, giving way to a more reasoned approach based on controlled physiological studies. The mechanisms and clinical significance of the association between gastrooesophageal reflux and asthma is now well understood.

There is an increased incidence of gastro-oesophageal reflux in asthmatic patients when compared with the 'normal population'. The quoted figures vary between $30-89 \%$ the consensus being around $50 \%$. All age groups are affected and the association is well recognised in children who have a shorter lower oesophageal sphincter and more frequent reflux. In infants it is particularly important to diagnose pulmonary aspiration which may be amenable to surgical treatment. In adults aspiration is uncommon and the respiratory symptoms must be explained by other mechanisms. The theory of 'micro-aspiration' of gastric contents into the airways has been put forward by Tuchman et $a l^{2}$ and elegantly backed by animal experiments. They showed that acid inhaled into the airways even in low concentrations caused far greater bronchoconstriction than gastric acid retained in the oesophagus. The detection of posterior laryngitis in patients with gastro-oesophageal reflux supports this theory, but the stumbling block to general acceptance has been the inability to show aspiration, using radioisotope techniques, in most patients. ${ }^{3}$

The oesophagus and the bronchial tree share embryological origins in the foregut and acid reflux may initiate bronchoconstriction by a vagally mediated reflex through their shared autonomic innervation. Mansfield and colleagues ${ }^{+}$found that acid infusion into the oesophagus in patients with gastro-oesophageal reflux and asthma caused a small but significant increase in airways resistance and a decrease in flow rate during forced expiration at $25 \%$ vital capacity. This response occurred only in asthmatics with active oesophagitis ${ }^{5}$ and could be reversed by antacids; in dogs vagotomy abolished any such effect. ${ }^{\circ}$ Acid in the inflamed oesophagus may stimulate exposed acid sensitive receptors which act through vagal afferents to the airways to initiate bronchoconstriction. The changes in respiratory function when acid is infused into the oesophagus, however, are small and can be detected only by the more sensitive tests of respiratory function such as airways resistance. In order to explain this and account for the lack of symptoms in such circumstances, the concept that acid in the oesophagus causes an increase in non-specific bronchial hyper-responsiveness has developed.

Wilson $e t a l^{7}$ investigated the effect of acid ingestion on bronchial hyper-responsiveness in 20 asthmatic children. They found a significant increase in histamine PC20 (the concentration of histamine required to produce a $20 \%$ fall from baseline in peak expiratory flow rate) in eight subjects all of whom had evidence of nocturnal gastro-oesophageal reflux on intraoesophageal $\mathrm{pH}$ monitoring. In adults with asthma and symptoms of gastro-oesophageal reflux, methacholine and isocapnic hyperventilation have been used to measure bronchial hyper-responsiveness and a similar effect has been detected. ${ }^{8}$ This response can be blocked by treatment with atropine before acid infusion. Acid in the inflamed oesophagus acting on exposed receptors and working via the vagus to cause an increase in bronchial hyper-responsiveness is the current most widely accepted hypothesis for the mechanism linking gastro-oesophageal reflux and asthma. This in turn makes the airways more sensitive to other external stimuli which may initiate bronchoconstriction.

Asthma may be the cause of gastro-oesophageal reflux in some patients. This argument suggests that increased transdiaphragmatic pressure during airflow obstruction can pump gastric contents into the oesophagus and that a low flat diaphragm, as found in hyperinflation, interferes with lower oesophageal sphincter function. Drugs used in asthma such as theophyllines and $\beta_{2}$ agonists can also have a detrimental effect on the antireflux barrier and further promote gastrooesophageal reflux. Experimental work, however, has shown that maximum inspiratory efforts in normal subjects can produce transdiaphragmatic pressures of $300 \mathrm{~cm} \mathrm{H}{ }_{2} \mathrm{O}$ without causing gastro-oesophageal reflux. In asthmatic patients 
taking theophylline, histamine induced bronchoconstriction has similarly been shown to have little effect. The changes in the mechanics of the chest wall during acute episodes of airflow obstruction may alter the predisposition to gastrooesophageal reflux in some patients. Gastro-oesophageal reflux as an exacerbating factor in asthma is probably more important, although the relationship is complex.

How much does this matter in clinical practice? A thorough investigation of this question has been performed by Ekström, Tibbling, and colleagues. ${ }^{9}$ In a group of patients with proven gastro-oesophageal reflux and moderate to severe asthma they were unable to show a causal relationship between documented episodes of reflux and symptoms of asthma, peak expiratory flow rate, or use of bronchodilators. ${ }^{10}$ During acid perfusion of the oesophagus in asthmatic patients with increased bronchial hyper-responsiveness they failed to induce symptoms of asthma or audible wheeze." There was, however, a statistically significant but small drop in forced expiratory volume in one second (FEV1), which correlated with the level of bronchial hyper-responsiveness and would support the postulated reflex mediated mechanism. Nocturnal pH monitoring in a group of patients with night time asthma and symptoms of gastro-oesophageal reflux showed no difference in respiratory symptoms or use of inhalers between those with reflux during the night and those without. ${ }^{9}$ They suggested that although there is an association between gastrooesophageal reflux and asthma, it is not important in most patients.

A variety of different treatments aimed at improving gastro-oesophageal reflux have been used in patients who also have asthma but their effect on respiratory symptoms is not clear. Kjellen $e t a l,{ }^{12}$ in an open study, suggested that general measures to treat gastro-oesophageal reflux (such as raising the head of the bed, losing weight and avoiding large meals) in combination with alginates improved asthma symptoms and reduced the use of bronchodilators, but they made no objective measurements of respiratory function, the control group were untreated, and a later placebo controlled trial of alginates did not confirm their findings. ${ }^{13}$ In a double blind placebo controlled trial of six weeks of cimetidine in 20 patients there was a significant improvement in asthma and oesophageal symptom score and a rise in nocturnal peak expiratory flow rate, but this amounted to only $25 \mathrm{l} / \mathrm{s}$ and was probably of limited clinical significance. ${ }^{1+}$ An open study of 15 patients treated with eight weeks of ranitidine was similarly inconclusive, with an improvement in asthma symptom score only at seven weeks and an increase in forced expiratory volume in one second only at eight weeks. ${ }^{15}$ More useful information for the clinician has been provided by Ekström et $a l^{16}$ who performed a double blind crossover study in 48 patients with asthma and symptoms of gastrooesophageal reflux, to evaluate the effect of four weeks treatment with ranitidine. They divided their patients into two groups, those with reflux associated respiratory symptoms, and those without. They noted a 'clinically modest but statistically significant improvement' in nocturnal asthma and daily use of bronchodilators, and a significant improvement in reflux symptoms after active treatment. The only factor that predicted which patients would benefit from treatment was the presence of reflux associated respiratory symptoms. Taking a good history from the patient is still the most effective way of selecting those who require treatment. Special attention should be paid when cough, wheeze or breathlessness occur at the same time as symptoms of gastrooesophageal reflux. We accept that in most cases the effect of treating such patients will be modest, however when dealing with 'brittle' asthma it is important to consider every relevant therapeutic avenue.

The studies of medical treatment of gastro-oesophageal reflux have been criticised because the regimens used are not effective in healing oesophagitis in a proportion of patients, and with this in mind work has begun with newer compounds such as cisapride and omeprazole. Cisapride improved respiratory symptoms in 20 children with gastro-oesophageal reflux and asthma, ${ }^{17}$ and there are case reports suggesting the effectiveness of omeprazole. Larger studies are underway but it is unlikely that these drugs will revolutionise the treatment of patients with gastro-oesophageal reflux and asthma, though they may become the treatment of choice for patients with reflux associated respiratory symptoms on the basis of their superior effect in treating oesophagitis.

It is logical when treating patients with asthma to try and avoid exacerbating their concurrent gastro-oesophageal reflux. Theophylline derivatives relax the lower oesophageal sphincter and may induce symptoms of reflux. This can reduce their efficacy in asthma by causing an acid induced increase in bronchial hyper-responsiveness and could theoretically lead to bronchoconstriction in some subjects. Selective $\beta_{2}$ agonists may also have a similar effect though this has not been documented in clinical practice.

A rational approach to treatment of patients with gastrooesophageal reflux and asthma would first select those with reflux associated respiratory symptoms. Treatment of their gastro-oesophageal reflux should be along standard lines, using general methods to avoid reflux and alginates. Failure of these simple measures is an indication to introduce an $\mathrm{H}_{2}$ receptor blocker. Ranitidine may be preferred to cimetidine in those in whom further treatment with theophyllines is considered essential, as the latter may induce toxic theophylline levels. Treatment of the asthma should include inhaled corticosteroids with $\beta_{2}$ agonists for symptomatic relief. Withdrawing theophyllines may improve oesophageal and possibly respiratory symptoms. Patients who are refractory to this regimen may benefit from cisapride or omeprazole. Surgical intervention is indicated only in cases of severe and intractable oesophagitis or documented recurrent pulmonary aspiration.

In summary there is good physiological evidence that the reflux of gastric acid into an inflamed oesophagus may cause a vagally mediated increase in bronchial hyperresponsiveness in patients with asthma. This causes an increase in bronchoconstriction in response to other stimuli and may make asthma control difficult. Patients who can relate their respiratory symptoms to episodes of reflux should have their oesophagitis treated.

J M GOLDMAN J R BENNETT

Hull Royal Infirmary,

Hull

Correspondence to: Dr J R Bennett,

Hull Royal Infirmary, Anlaby Rd, Hull HU3 2JZ.

1 Bray GW. Recent advances in the treatment of asthma and hay fever. Practitioner 1934; 34: 368-79.

2 Tuchman DN, Boyle JT, Pack AI. Comparison of airway responses following tracheal or oesophageal acidification in the cat. Gastroenterology 1984; 87: $872-8$

3 Ghaed N, Stein MR. Assessment of a technique for scintigraphic monitoring of pulmonary aspiration of gastric contents in asthmatics with gastroesophageal reflux. Ann Allergy 1979; 42: 306-8.

4 Mansfield LE, Stein MR. Gastroesophageal reflux and asthma: a possible reflex mechanism. Ann Allergy 1981; 41:224-6.

5 Spaulding LS, Mansfield LE, Stein MR, Sellner JC, Gremillon DE. Further investigation of the association between gastroesophageal reflux and bronchoconstriction. F Allergy Clin Immunol 1982; 69: 516-21.

6 Mansfield LE, Hameister AH, Spaulding LS, Smith NJ, Glab N. The role of the vagus nerve in airway narrowing caused by intraesophageal hydrochloric acid provocation and esophageal distension. Ann Allergy 1981; 47: 431-4.

7 Wilson NM, Charrette L, Thomson AH, Silverman M. Gastroesophageal ilson NM, Charrette L, Thomson AH, Silverman
reflux and childhood asthma. Thorax $1985 ; 40: 592-7$.

8 Herve O, Denjean A, Jian R, Simmoneau G, Duroux P. Intraesophageal perfusion of acid increases the bronchomotor response to metacholine and to perfusion of acid increases the bronchomotor response to metacholine and to 134: $986-9$.

9 Ekström T. The importance of gastro-oesophageal reflux as a trigger factor in bronchial asthma. Linköping University Medical Dissertations 1988; 278.

10 Ekström T, Tibbling L. Gastroesophageal reflux and the triggering of bronchial asthma: negative report. Eur f Respir Dis 1987; 71: 177-80.

11 Ekström T, Tibbling L. Gastro-oesophageal reflux and nocturnal asthma. Eur Respir F 1988; 1: 636-8. 
12 Kjellén G, Tibbling L, Wranne B. Effect of conservative treatment of oesophageal dysfunction on bronchial asthma. Eur 7 Respir Dis 1981; 62: $190-7$.

13 Noseda A, Jonas C, Deltenre M, Prigogine T, Schmerber J, Yernault JC International symposium on gastroesophageal reflux and respiratory disInternational symposium on gastroesophageal reflux and respiratory dis-
orders [Abstract]. Brussels. 1988: 14 . 14 Gorder.

Goodall RJR, Earis JE, Cooper DN, Bernstein A, Temple JG. Relationship
between asthma and gastro-oesophageal reflux. Thorax 1981; 36: 116-21.

15 Harper PC, Bergner A, Kaye MD. Antireflux treatment for asthma. Improve- ment in patients with associated gastroesophageal reflux. Arch Intern Med $1987 ; 147: 56-60$.

16 Ekström T, Tibbling L. Effects of treatment on patients with asthma and a history of gastro-oesophageal reflux: a double blind cross over trial. Thorax 1989; 44: 19-23.

17 Saye $\mathrm{P}$, Forget $\mathrm{D}$. Effect of cisapride on esophageal $\mathrm{pH}$ monitoring in children with reflux associated bronchopulmonary disease [Abstract]. First International Symposium on gastroesophageal reflux and respiratory disorders. Brussels. 1988: 28 . 